\title{
Absolute science of siddha sastric drugs- An experimental proof
}

\begin{abstract}
Shastric choorana of siddha system of medicine follows an absolute science with reference to the drug release of various herbs used in the formulation. We have conducted a study using the OD value vis-à-vis the rate of release vis-à-vis time. Two most effective drugs Trikadu and Triphala were taken for the study. Findings validate the existence of incredible science in Siddha shastric drugs.
\end{abstract}

Keywords: Trikadu, Triphala, poly herbal- time release, eExtractable matter
Volume 12 Issue 2 - 2019

\author{
Soundharya R, Aruna V,Amruthavalli GV, \\ Gayathri R
}

JRK's Research \& Pharmaceuticals Pvt. Ltd, India

Correspondence: Aruna V, JRK's Research \& Pharmaceuticals Pvt. Ltd, No. 18 \& 19 Perumal Koil street, Kunrathur, Chennai600069, India, Email aruna_v@jrkresearch.com

Received: August 25, 2018 | Published: March 28, 2019

\section{Introduction}

The usefulness of various herbs in treating the health care problems of human beings is well known to native human populations all over the world. During the ancient times the scientific knowledge of various diseases was unknown and so were no proper medicines available for the treatment. Man had attempted to use several resources around him to manage the health problems. ${ }^{1-3}$

With the advent of modern science, the existence of several therapeutically active molecules in herbal sources have been identified and were synthesised as drugs since the relative abundance of all such therapeutically active compounds were abysmally low in the herbal sources. Further the isolation and purification all such therapeutically active compounds are also extremely costly and that has compelled the industries to go for synthesis. ${ }^{4-6}$

The herbal drugs are prepared either with single herb or with combination of several herbs at varying proportions. The poly herbal drugs were prepared based on the established therapeutic value of herbs at individual level and translating a possible rationale that such poly herbal preparations will be more effective than single herb based preparations. However therapeutic efficacy of poly herbal preparations over the respective individual herbs is unclear. In most occasions the presence of more herbs in poly herbal drugs has always outscored science and has captivated human imagination therefore poly herbal preparations are blindly believed to be superior over single herb formulation. ${ }^{7-9}$

The rate of dissolution of individual herbs from poly herbal mixture can vary greatly with reference to the dissolution of individual herbs thus affecting the therapeutics of poly herbal drugs. The present study is aimed to validate the above hypothesis through colorimetric and release dynamics of the soluble metabolites from herbs used in two poly herbal traditional drugs such as Trikadu and Triphala. Findings are presented in the paper.

\section{Materials and methods}

\section{Details of Trikadu}

$\begin{array}{ll}\text { Piper nigrum } & -33.33 \mathrm{~g} \\ \text { Zingiber officinalae } & -33.33 \mathrm{~g} \\ \text { Piper longum } & -33.33 \mathrm{~g}\end{array}$

\section{Details of Triphala}

Phyllanthus emblica $\quad-33.33 \mathrm{~g}$

Terminalia chebula $\quad-33.33 \mathrm{~g}$

Terminalia bellerica $\quad-33.33 \mathrm{~g}$

\section{Preparation of water soluble constituents of individual herbs}

The individual herbs in Trikadu and Triphala were weighed accurately to $1 \mathrm{gm}$. The $1 \mathrm{gm}$ of each herbal powder was separately incorporated with $100 \mathrm{ml}$ of double distilled water and was heated to $100 \mathrm{c}$. The heating process was done for 10 and 30 minutes and the mixture was filtered and then centrifuged at $1000 \mathrm{rpm}$ for 15 minutes. The final filtrate was used for the experiment. The filtrate was read colorimetrically at $500 \mathrm{~nm}$. Subsequent to colorimeter reading a known quantity of filtrate was taken in a pre-weighed China dish and was heated further to evaporate out the water. The final yield of the extract was weighed and recorded.

Similarly the both the Trikadu and Triphala were also subjected to the above process and the OD \& final yield of the extract were recorded.

\section{Preparation of standard curve of Trikadu, and its individual herbs}

Individual herbs of Trikadu were weighed accurately to 10,20 , $30,40,50,60,70,80,90$ and 100 and were reconstituted in water accordingly to achieve the above weights per millilitre concentration. Similarly Trikadu was also weighed accurately to $10,20,30,40,50$, $60,70,80,90$ and 100 and were reconstituted in water accordingly to achieve the above weights per millilitre concentration.

The OD of all the above were read at $500 \mathrm{~nm}$ through a colorimeter.

\section{Preparation of standard curve Thripala and its individual herbs}

Individual herbs of Triphala were weighed accurately to 100, 200, $300,400,500,600,700,800,900$ and 1000 and were reconstituted in water accordingly to achieve the above weights per millilitre concentration. Similarly Triphala was also weighed accurately to $100,200,300,400,500,600,700,800,900$ and 1000 and were reconstituted in water accordingly to achieve the above weights per millilitre concentration. 
The OD of all the above were read at 500nm through a colorimeter.

\section{Results}

Various raw drugs of Trikadu such as Piper nigrum, Zingiber officinalae Piper longu when tested for the release of metabolites between 10 and 30 minutes we did not find any great difference. The sum of the total extractable matter of all the 3 herbs was comparable with the extractable matter of the finished product Trikadu (Table 1).

Table I The extractable matter of Trikadu and its ingredients

\begin{tabular}{llllll}
\hline \multirow{2}{*}{ Material Name } & Weight & \multicolumn{2}{c}{ I Omin } & \multicolumn{3}{c}{$30 \mathrm{~min}$} \\
\cline { 3 - 6 } & in gm & OD & Yield & OD & Yield \\
\hline Piper nigrum & I & 0.26 & $0.06 \mathrm{~g}$ & 0.29 & $0.07 \mathrm{~g}$ \\
Zingiber officinalae & $\mathrm{I}$ & 0.07 & $0.15 \mathrm{~g}$ & 0.09 & $0.15 \mathrm{~g}$ \\
Piper longum & $\mathrm{I}$ & 0.12 & $0.08 \mathrm{~g}$ & 0.14 & $0.08 \mathrm{~g}$ \\
Trikadu & 3 & 0.19 & $0.32 \mathrm{~g}$ & 0.24 & $0.38 \mathrm{~g}$ \\
\hline
\end{tabular}

Various raw drugs of Triphala such as Phyllanthus emblica, Terminalia chebula \& Terminalia bellerica when tested for the release of metabolites between 10 and 30minutes we did not find any great difference. The sum of the total extractable matter of all the 3 herbs was comparable with the extractable matter of the finished product Triphala (Table 2).

Table 2 Total extractable matter of all the 3 herbs was comparable with the extractable matter of the finished product Triphala

\begin{tabular}{llllll}
\hline \multirow{2}{*}{ Material Name } & \multirow{2}{*}{$\begin{array}{l}\text { Weight in } \\
\text { gm }\end{array}$} & \multicolumn{1}{c}{ IOmin } & \multicolumn{3}{c}{ 30min } \\
\cline { 2 - 6 } & OD & Yield & OD & Yield \\
\hline Phyllanthus emblica & I & 0.43 & 0.45 & 0.45 & 0.45 \\
Terminalia chebula & I & 0.32 & 0.57 & 0.41 & 0.6 \\
Terminalia bellerica & I & 0.40 & 0.41 & 0.4 & 0.42 \\
Triphala & 3 & 0.90 & 1.12 & 1.01 & 1.35 \\
\hline
\end{tabular}

\section{Discussion}

The present study has revealed an intriguing face of poly herbal drugs that are widely used in the native system of medicine like Ayurveda and Siddh. ${ }^{10}$ It is always assumed that poly herbal drugs are therapeutically better effective than the individual herbs used in such formulations. The sum of the extractable matter of the individual herbs at given weight and time has agreed perfectly with the finished formulation- Trikadu and Tripala of equal weight and time (Figure 1 \& 2).

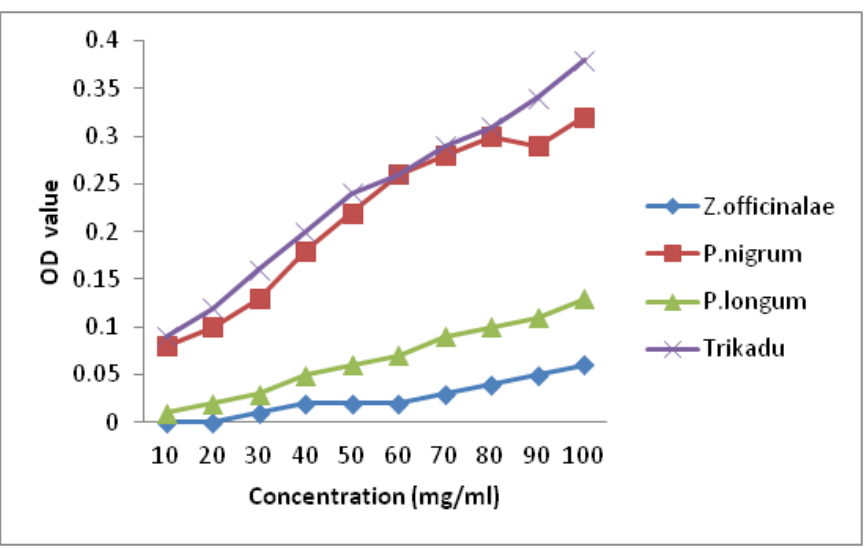

Figure I Linearity Graph of Trikadu and its ingredients.

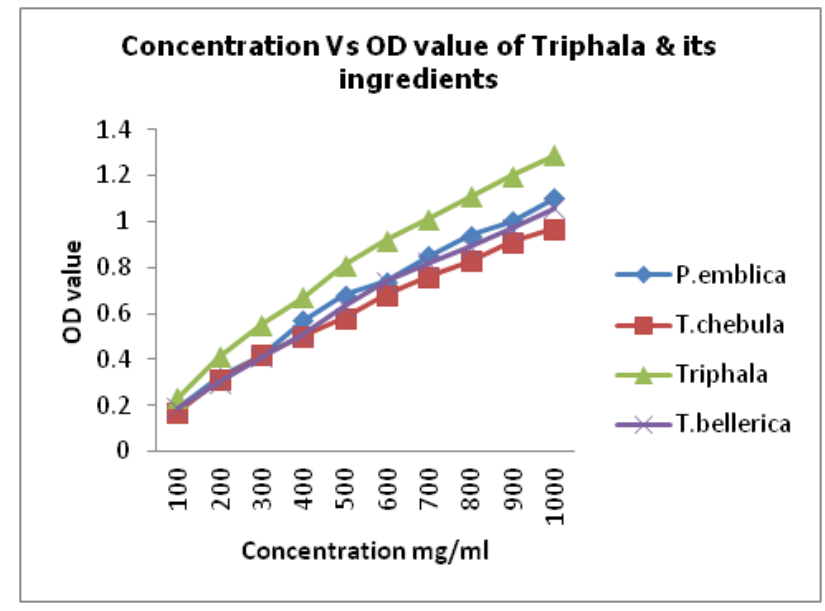

Figure 2 Linearity Graph of Triphala ingredients.

\section{Conclusion}

The above findings clearly show that the release of the metabolites is great even from poly herbal preparations like that of individual herbs. Irrespective of the possible competition among variable soluble constituents of different herbs that are assumed to affect their elution in the finished formulation, the Siddha shastric drugs proves a difference science. The rate of elution of individual herbs vis-à-vis finished formulation did not differ greatly between 10 and 30minutes which suggest that neither time nor the likely competition among different herbs in the finished formulation.

We have used $3 \mathrm{gm}$ of Trikadu (1 gm each of Piper nigrum, Zingiber officinalae, Piper longum) and Tripala (1gm Phyllanthus emblica, Terminalia chebula, Terminalia bellerica) in $100 \mathrm{ml}$ for comparing its OD and concentration values as against $1 \mathrm{gm}$ in $100 \mathrm{ml}$ each of Piper nigrum, Piper longum and Zingiber officinalae, Terminalia chebula, Terminalia bellerica and Phyllanthus embilca individually.

The findings clearly show that the poly herbal drugs are likely to be more effective than $t$ individual herbs from the premise of the elution quotient of the metabolites.

As expected we have observed a small deviation between OD value $\&$ concentration and this may be due to the possible oxidation/ other chemical changes taking place in the herbal extracts when stored in aqua base. The scope of the present study is neither to authenticate nor to establish the role of colorimeter in the quantification of herbal metabolites. However in the presence of the standard graph plotted with definite concentration and OD values of the respective herbs, Trikadu and Thripala, findings of the present study gain greater scientific sanctity.

The herbal drug fortification made with the assumption of combining two or more herbs that contains similar therapeutic value as assumed by ancient Siddhars holds great locus standi with the findings of our present study.

Two or more therapeutically active herbs in all likelihood would give greater therapeutic efficacy than the individual herbs because the release pattern of the metabolite from the poly herbal ecosystem to mono herbal ecosystem.

The above findings were obtained purely from the laboratory environment but whether the biological system can operate differently 
or can facilitate differently to potentiate the maximum elution of metabolites from different herbs is unclear. Further 'together elution' whether can bring certain chemical changes/newness is not yet established.

Considering the enormous documentation of poly herbal drugs in ancient Ayurveda and Siddha systems of medicine suggest the possibility that the biological system may facilitate the better elution than the laboratory conditions.

Since the global population is aggressively marathon towards Ayurveda and Siddha system of medicine such possibility cannot be negotiated or dismissed because both the above systems were evolved with divine grace and were handed over to the present generation by spiritually evolved souls.

\section{Acknowledgments}

None.

\section{Conflicts of interest}

Author declares there is no conflict of interest towards this article.

\section{References}

1. World Health Organization. WHO traditional medicine strategy 20022005. Geneva: World Health Organization; 2002.
2. Ravishankar B, Shukla VJ. Indian Systems of Medicine: A Brief Profile. Afr J Tradit Complement Altern Med. 2007;4(3):319-337.

3. Dahanukar SA, Kulkarni RA, Rege NN. Pharmacology of Medicinal Plants and Natural Products (1994-98). Indian $J$ Pharmacol. 2000;32:S81-S118.

4. Indian system of medicine and homoeopathy. In: Prasad L, Editor. Traditional Medicine in Asia, South East Asia, New Delhi, India: WHO - Regional Office; 2002.

5. Winslow LC, Kroll DJ. Herbs as medicines. Arch Intern Med. 1998;158(20):2192-20199.

6. Heinrich M, Barnes J, Gibbons S, et al. Fundamentals of Pharmacognosy and Phyto pharmacy. Edinburgh, UK: Churchill Livingstone; 2004. p. 360

7. Singh J, Bagchi G, Khanuja SPK. GMP for Botanicals. In: Verpoorte R, Mukherjee, Editors. New Delhi, India: Business Horizons Ltd; 2003.

8. Houghton PJ, Mukherjee PK. Evaluation of Herbal Medicinal Productsperspectives on Quality, Safety and Efficacy. UK: Pharmaceutical Press, Royal Pharmaceutical Society of Great Britain; 2009.

9. Graul AI, Revel L, Barrionuevo M, et al. The year's new drugs \& biologics - 2008. Drug News and Perspectives. 2009;22(1):7-29.

10. Parasuraman S, Thing GS, Dhanaraj SA. Polyherbal formulation: Concept of Ayurveda. Pharmacogn Rev. 2014; 8(16):73-80. 